Noticias y Comentarios

\title{
Symposium sobre la Orden de San Jerónimo
}

Durante los días I al 5 de septiembre de 1999 se celebró en la madrileña localidad de San Lorenzo del Escorial el Symposium titulado "La Orden de San Jerónimo y sus Monasterios. Espiritualidad, historia, arte, economía y cultura de una Orden religiosa ibérica". Como tal rúbrica indica, este interesante evento pretendió realizar un análisis multifocal e interdisciplinar sobre la Orden Jerónima y su rico patrimonio histórico, artístico y de producción escrita. Su organización -en la que debemos destacar, un año mas, el buen hacer del Padre agustino Francisco Javier Campos y Fernández de Sevillacorrió a cargo del Instituto Escurialense de Investigaciones Históricas y Artísticas, además de contar con el patrocinio de la propia Comunidad Jerónima y de los Caballeros del Monasterio de Yuste. El resultado del Symposium, así como sus principales conclusiones, se recoge en dos voluminosos tomos de actas ', que constituyen la decimosexta entrega de la Colección del ya nombrado Instituto Escurialense. La lección inaugural, pronunciada por Fray Ignacio de Madrid, O.S.H. del Monasterio de Santa María del Parral (Segovia), llevó por título "La Orden de San Jerónimo en perspectiva histórica". No podía ser de otra manera: el Padre Ignacio expuso, a modo de síntesis contextual imprescindible, un excursus introductorio al devenir histórico de la Orden, desde San Bartolomé de Lupiana a nuestros días. Al auge de fundaciones de las dos primeras centurias, y la incorporación de los monasterios lusos en la tercera, siguió un proceso de "decadencia y relajación" que culminó -tras los avatares y expulsiones sufridos durante la Guerra de Independencia- con la fatídica fecha de 1835: la Desamortización. En 1854 Isabel II expide un real decreto que dispone el restablecimiento de una Comunidad jerónima en El Escorial; otro tanto sucede en 1925, en Santa María del Parral. Hoy son sólo dos -Parral y Yuste- los monasterios de jerónimos habitados, frente a los diecisiete femeninos, entre los que destacan, en algunos casos, recentísimas fundaciones, caso de Nuestra Señora de Belén (Toral de los Guzmanes, León, 1990). Por lo que se refiere al grueso de comunicaciones fueron 48 las intervenciones que tuvieron lugar $y$, pese a la interdisciplinariedad existente, podemos a grandes rasgos agruparlas en cinco ejes temáticos:

I. Historia: v.gr. "Novicios, Maestros y la obra de Fray José de Sigüenza", J. Carlos Vizuete Mendoza; "La figura del P. General en la Orden de San Jerónimo", Fernando Pastor Gómez-Cornejo.

II. Arte: v.gr. "El Monasterio de San Bartolomé de Lupiana (Guadalajara): el claustro de Covarrubias", Teresa Díaz Díaz; "Trasuntos de grabados de Durero en la sillería del Monasterio de Santa María del Parral o de las Huertas, en Segovia", Ángel Rojo Sanz.

III. Fuentes: v. gr. "Monasterio de Yuste: Fuentes documentales", Teodoro Martín Martín; "Fuentes para la Historia de la Orden Jerónima: D. Juan Pacheco y el Monasterio de Santa María del Parral", Manuel Marcos Aldón y Ricardo Víctor Blázquez Ruz.

IV. Bibliotecas monásticas: v.gr. "La Biblioteca del Monasterio Jerónimo de San Miguel y los Reyes de Valencia", Carmen Rodrigo Zarzosa; "La Biblioteca del Monasterio de Sant Jeroni de la Murtra", Jaime Aymar Ragolta.

V. Música: v.gr. "La teoría musical en los monasterios jerónimos (siglos XV-XIX). Notas bio-bibliográficas", María Sanhuesa Fonseca; "Las Misas del P. Antonio Soler: Presentación y estudio", Eutimio Bullón Pastor.

Entre las aportaciones revistieron singular interés las de los expertos en temática jerónima -Sebastián García, José Vicente de Frías Balsa, Jaime Aymar Ragolta, Manuel Barra Rodríguez-, y las de docentes e investigadores de la talla de Antonio Linage Conde o
Rafael Vázquez Lesmes, entre otros. Pero destaca entre todas ellas la comunicación del Padre Javier Campos que, bajo el título "Quinta Parte de la Historia de la Orden de San Jerónimo(|676-1777), constituye la introducción a la esperada edición de la obra homónima que vió la luz con motivo del Symposium. La lección de clausura corrió a cargo de Ramiro Flórez, de la Fundación Universitaria Española. Su título:"'La Melancolía de las piedras (El descontento de Arias Montano en El Escorial y entre los jerónimos)". Se cerraba así este Symposium cuyas conclusiones quedan recogidas en unas Actas que vienen a incrementar y actualizar -lejana ya la aparición en la década de los setenta de los famosos Studia Hieronimiana- el acervo de conocimientos sobre esta Orden.

\section{Carlos Benjamín Pereira Mira}

Becario de Investigación de la Facultad de Geografía e Historia de la Universidad de Oviedo

I. Campos y Fernández de Sevilla, F. J. (dir.), La Orden de San Jerónimo y sus Monasterios. Espiritualidad, historia, arte, economía y cultura de una Orden religiosa ibérica. Actas del Symposium, I/5-IX1999. Madrid: Instituto Esculturialense de Investigaciones Históricas y Artísticas, 1999. 1152 páginas. 